\title{
O DESIGN DE INFORMAÇÃO COMO INSTRUMENTO DE INCLUSÃO SOCIAL
}

\author{
Maria João Palma' \\ Airton Castagna² \\ Katia Avelar ${ }^{3}$
}

\section{RESUMO:}

Trata-se de estudo no âmbito da leitura e formação de leitores. O foco da pesquisa é o design de informação como princípio básico e facilitador para a aquisição de conhecimento por parte de indivíduos que necessitam ser incluídos socialmente. Será abordado o modo pelo qual o design da informação propicia maior assimilação de conteúdos por parte dos leitores, de modo a garantir o prazer da leitura e, assim, torná-la atrativa, favorecendo a absorção de conhecimentos e a ressignificação e/ou interpretação de conteúdos. Entende-se por design de informação toda a forma de aplicação e organização da informação, baseada nos conceitos da diagramação e do planejamento visual. Neste sentido, é que se torna importante a discussão e a troca de ideias e experiências nesta área, pois sem o acesso de muitos grupos à leitura, a promoção da cidadania, no mundo de hoje, torna-se inviável. A facilitação proporcionada pelo design garante ampliar o volume de leitura das pessoas, na medida em que os meios, ou recursos, de sua realização são oferecidos.

\section{PALAVRAS-CHAVE:}

Design social, leitura, informação, conhecimento, inclusão

\section{ABSTRACT:}

It is a study in the ambit of reading the formation and readers. The focus of the research is the design of information as basic principle and facilitator for the acquisition of knowledge by individuals that need to be socially included. Will address the way in which information design provides greater assimilation of the content from readers, to ensure the enjoyment of reading and thus make it attractive, favoring the absorption and reframing of knowledge and / or interpretation of content. It is understood by information design throughout the application form and information organization based on the concepts of layout and visual planning. In this sense, is that it is important to discuss and

$1 \quad$ Aluna do Programa de Pós-Graduação em Desenvolvimento Local da UNISUAM.

2 Professor do Programa de Pós-Graduação em Desenvolvimento Local da UNISUAM.

3 Professor do Programa de Pós-Graduação em Desenvolvimento Local da UNISUAM. 


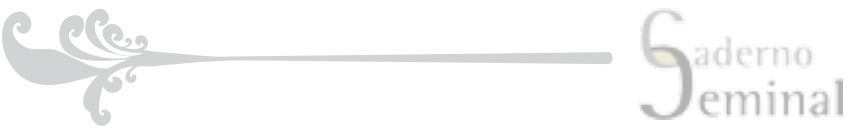

exchange ideas and experiences in this area, because without access to the reading of many groups, the promotion of citizenship in today's world, it is not feasible. The design ensures facilitation provided by expanding the volume of reading people, in that the means or resources of its realization are offered.

\section{KEYWORDS:}

Social design, reading, information, knowledge, inclusion

\section{Introdução:}

Em consonância com Abad, Braida e Ponte (2009, p. 2197), cada vez mais, os designers têm congregado signos táteis, gustativos e olfativos aos seus projetos, a fim de criar objetos mais complexos e mais acessíveis, que permitam aos usuários tornarem-se mais interativos e experimentarem momentos de mais profunda imersão. "Tais projetos tornam-se, portanto, mais sinestésicos, aguçam uma maior quantidade de sentidos possíveis, ampliam as possibilidades de representação e possibilitam um aumento da eficácia da comunicação".

Ainda de acordo com as autoras, "nessas interrelações do sistema sígnico, traduções intersemióticas são realizadas de matriz para matriz, de meio para meio, em um processo constante de crescimento e criação." (ABAD, BRAIDA\& PONTE, (2009, p. 2197). São os sistemas compostos pelos signos sonoros, visuais, verbais, olfativos, gustativos e táteis, quase sempre misturados e articulados entre si, materializados nos artefatos resultantes dos processos de projeto, que se denominam sistemas híbridos do design.

Hierarquia, significado e pragmatismo são caminhos necessariamente percorridos pelo design de informação, sem priorizar um em detrimento do outro, pois todos têm a mesma importância, já que, metodologicamente, viabilizam as respostas às perguntas: o quê, como, e para quê? A hierarquia, ou ordem de importância, é que determina o assunto que tem mais interesse para um dado auditório, (PERELMAN, 2005), ou para uma dada comunidade (com características culturais, ambientais e políticas específicas). Dependendo do auditório, ou da comunidade, o modo de aceitar ou reter a informação é completamente diferente, Daí que o modo de comunicá-la também tem importância fundamental.

Neste ponto, chega-se à idéia de significado, pois do ponto de vista semiótico, o modo como os intérpretes lêem os "signos interpretantes" (PIERCE, 1979), ou o modo como os signos reunidos produzem sentidos para os intérpretes depende também do modo como estão dispostos nos artefatos criados, ou ressignificados. Como observa Walther-Bense (2000, p.85): "o homem não se relaciona apenas com as coisas, mas também com os signos. Seu conhecimento é muito mais um mundo de signos do que um mundo de objetos". 


\section{Sistemas intersemióticos a favor da comunicação}

McLuhan (1969), nas décadas de cinquenta e sessenta, estudou e discutiu o papel e o impacto dos novos meios de comunicação. Afirmava que o jornal (aqui entendido como veículo propagador de informação) já, naquela época, tendia para uma forma participante. O autor já chamava a atenção para a imagem em mosaico. Dizia, contudo, que a relevância não estava tanto na imagem, mas no recorte que era dado aos acontecimentos. "Como massa de tópicos descontínuos e desconexos... que acolhe a inclusão de muitas tribos e a diversidade das visões particulares", (MCLUHAN, 1969, p. 242).

Significava uma participação efetiva da comunidade leitora ou decodificadora, uma vez que intensificava a relação entre palavra e imagem, através da valorização de elementos estéticos. "Na verdade, quando o autor se refere a esse mosaico como "ícone estrutural do jornal", forma e conteúdo se congraçam e aí já se está, nos dizeres de McLuhan, no campo da" poética do jornal".

Pensar em como interpretar esse processo de comunicação e de que maneira isso pode representar a vida social, política e econômica da comunidade, bem como o modo como comunicar um conteúdo - para que fique prazeroso na leitura - deve ser um atrativo para os designs na composição gráfica. Tratase da manipulação de aglomerados de signos, no sentido de gerar unidades significantes, converter necessidade em conceito e conceito em um objeto que participará do cotidiano da comunidade.

Um design de informação deve-se considerar um tradutor, um materializador de idéias, capaz de fazer um tipo de interface que torna uma embalagem num código, que elabora um rótulo que indica o conteúdo daquele volume, sua procedência e forma de abrir, sugerindo o uso. A ideologia desse diagramador que acaba de ser chamado de "tradutor", mas que está mais para um reeditor, é alimentada pela apropriação de diversas linguagens que vão servir para comunicar algo a outro. Essas linguagens utilizadas para estabelecer a comunicação são as ferramentas de uma diagramação que se pode chamar de generosa.

É generosa porque vai estreitar a relação entre indivíduos. Vai facilitar e estabelecer contato direto, sincero e saudável para um único fim: comunicar, transmitir e instruir, tendo a generosidade como fio condutor. Até na forma subliminar pode-se admitir o uso da generosidade para aproximar a mensagem ao leitor. Quase como sussurrar ao ouvido de alguém a explicação do conteúdo escrito, da história contada. Pode-se chamar e marcar a diagramação generosa como uma atividade da comunicação que contribui para o crescimento das pessoas, por propiciar o conhecimento e aliá-lo à satisfação que gera uma boa leitura.

Na passagem do movimento concreto para o neo-concretismo, artistas brasileiros como Amilcar de Castro, escultor que marcou a história da diagramação da 


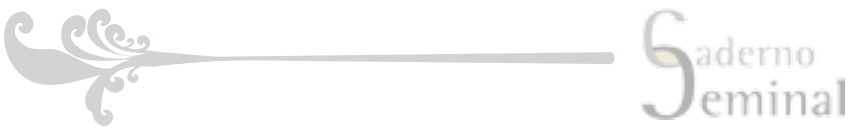

notícia, compartilhavam a compreensão comum da interferência da arte na vida cotidiana, tentavam provar que a arte tinha que ser mais sensível e de maneira indelével registraram uma época com a geometria sensível. (COUTINHO in PUCU, 2008, p 225). Assim, esse marco na história da diagramação pode ser explicado como uma entrada de ar novo, que veio arejar os textos, as notícias, facilitando a leitura. Tanto entre as colunas de texto que compõem as colunas ou até mesmo em grandes áreas abertas, os espaços em branco levam o leitor ao prazer de ouvir o eco das palavras que passeiam na sua mente, enquanto formam opinião e significado próprios.

Deste modo, podemos entender a generosidade como uma ação que mais se confunde com um sentimento capaz de inspirar diversas manifestações da arte. Estaria aqui a grande diferença entre aqueles que defendem que a arte deveria seguir uma teoria, que posteriormente se aplicaria a situações com fins utilitários, para o cumprimento de uma função, com aqueles que acreditam numa fusão entre arte e vida. Sem a preocupação em dar utilidade à arte e sim tornar o útil artístico. A pretensão é obedecer ao olhar, é alcançar a sensibilidade estética, através da largueza de percepções e pensamento visual e utilizá-la a favor da comunicação. É como converter num único ato a experimentação e experimentar-se. Como se fosse impossível separar o ser do fazer.

\section{A prática da diagramação como inclusão}

Conforme Bocchini (2011, p. 4), "a leitura rápida e compreensiva deveria ser um objetivo do ensino e deveria ser favorecida pelo projeto gráfico dos livros didáticos". A autora chama atenção para alguns aspectos que confirmam a relevância das questões discutidas neste trabalho. Segundo ela, a programação visual do livro exerce função determinante no processo de ensino/aprendizagem. "Não só a composição do texto e a diagramação, mas também o formato do livro e a forma de encadernação podem facilitar ou dificultar a leitura." (BOCCHINI, 2011, p. 5).

Tendo em vista as palavras de Bocchini sobre a leitura e o conseqüente aprendizado do que se lê, pode-se afirmar que a diagramação é importante para a clareza e eficiência da leitura que conduz ao aprendizado, pois existem elementos sobre os quais é preciso decidir quando se pretende garantir a leitura confortável para crianças e leitores em desenvolvimento. Entre os elementos listados pela autora, figuram: o tipo das letras e suas variações (tipologia), a entrelinha, o comprimento da linha, a regularidade da composição, a relação de contraste entre o texto e o fundo. Ainda pode-se incluir, como fator importante, o tipo de alinhamento, adequado ao conteúdo e à quantidade de texto.

Para manter o objetivo principal que é criar interesse visual, o cuidado deve começar quando se ajustam as proporções das margens, ou quando uma estrutura assimétrica cria mais espaço em branco, onde os olhos podem 
descansar. Ou ainda, quando tratamos a importância do conteúdo. É possível afirmar que existe mesmo uma espécie de hierarquia geral dentro de uma página diagramada. Tal hierarquia poder ser notada em pequenas alterações no peso dos elementos, na ênfase ou no alinhamento que podem criar enormes diferenças e, assim, fazer com que o menos seja mais. Isto é, que a conjugação entre os elementos visuais favoreça o maior aproveitamento da leitura enquanto forma de apreensão de conteúdos no momento da leitura.

É também necessário analisar os aspectos do livro e as regras básicas da legibilidade, entre as várias características capazes de tornar um livro mais ou menos adequado ao que se propõe, podemos listar: curvatura da página, que pode dificultar a leitura causando desconforto ao aluno; incidência de luz, o que, a depender do arranjo visual, pode afetar a compreensão; opacidade e gramatura do papel, o que pode, por exemplo, evitar sombras de textos e figuras do verso ou da página seguinte; tamanho do livro, para o manuseio, por exemplo, ou a colocação na mesa, carteira e demais suportes escolares; peso, que torna o transporte mais ou menos penoso, lembrando que no caso brasileiro, os estudantes têm que levar e trazer os livros de casa para a escola.

Voltando a McLean (1997, p 44-45), há três regras básicas a serem observadas quando se pretende uma boa legibilidade. São elas:

o tipo sem serifa (pequenos prolongamentos nas extremidades das letras) é intrinsecamente menos legível do que o serifado; um tipo romano bem desenhado em maiúsculas e minúsculas é mais fácil de ler do que suas variações (itálico, negrito, só maiúsculas, versões condensadas ou expandidas); as palavras devem estar próximas umas das outras (separadas tanto quanto a largura da letra "i") e deve haver mais espaço entre as linhas do que entre as palavras. Mas acima de tudo garantir que o projeto gráfico antecipe e complemente o que está representado no conteúdo.

Conforme Jan Tschichold (2007, p. 31), um diagramador de livro deve ser um servidor leal e fiel da palavra impressa. É sua tarefa é criar um modo de apresentação, cuja forma não ofusque o conteúdo e nem seja indulgente com ele. O autor faz uma série de recomendações, tais como: escolher uma fonte bem ajustada ao texto; projetar uma página primorosa, idealmente legível, com margens harmonicamente perfeitas, impecável espacejamento de palavras e letras; escolher corpos de tipo ritmicamente corretos para folhas de rostos e títulos, e compor as páginas em que há títulos de seção e de capítulos genuinamente belas e graciosas, no mesmo tom da página de texto. Por esses meios um diagramador de livro pode, segundo o autor, contribuir muito para a fruição de uma valiosa obra da literatura.

Do mesmo modo, o livro didático precisa ser dinamizado por recursos hipertextuais, por exemplo, se não quiser perder a atenção do estudante. Hipertexto aqui se refere à utilização interativa de elementos visuais constantemente associados a conceitos, tabelas, ilustrações, dados históricos e exemplos. 


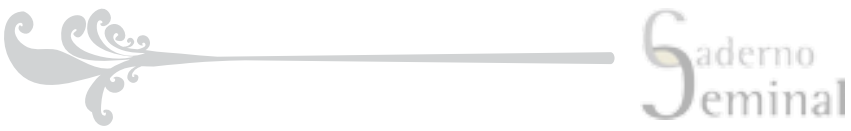

Visto como mero recurso facilitador da apreensão da informação, o design da informação pode ir além, a fim de produzir conhecimento e descodificar ou traduzir conteúdo específico que antes atendia exclusivamente a especialistas de determinada área de entendimento e pensamento. O design da informação situa-se na fronteira ou entroncamento dos saberes, pois pode esmiuçar uma informação complexa e torná-la simples para, assim, gerar um entendimento geral ou que, de certa forma, atinja uma grande maioria de leitores ou prováveis leitores.

Ora, quando a leitura forma pessoas capazes de pensar, criar e desenvolver, é imprescindível que a percepção de mundo do leitor esteja coerente com a realidade em que ele vive. Assim, para formar um leitor através da linguagem gráfica é necessário e fundamental verificar a capacidade que este tem de interpretar e compreender signos. Para então se chegar ao pragmatismo, que é a finalidade última, o momento em que se destina os sistemas de informação ao seu público leitor.

Além de perguntar e responder a estas perguntas, o quê, como e para quê, a intenção desta reflexão é também identificar as principais dificuldades da leitura que podem estar relacionadas com a diagramação e, ainda, indicar algumas premissas básicas para um manual de avaliação de material didático e livros instrutivos. Construir parâmetros e regras que irão conduzir os manuais de construção da forma desse material.

\section{A leitura entre a educação e a escola}

Parte-se do pressuposto de que o hábito da leitura se adquire na escola, através de sistemas educacionais que, de forma estratégica, hão de ser determinantes no aprendizado e na formação dos indivíduos, de modo que estes se tornem socialmente incluídos. A educação, sobretudo em uma sociedade como a brasileira que ainda possui contingentes fora da escola, ou que, grande parte se evade antes mesmo de completar os estudos fundamentais, precisa de estratégias variadas de inclusão e de viabilização do acesso à cidadania e acesso ao livro é uma delas.

A tão sonhada mobilidade social, no sistema capitalista, depende sobremaneira da escolarização. Pelo menos a inclusão mais consistente, regular e duradoura. 0 aprendizado que se oferece com a escolarização é transmitido em grande parte através de livros didáticos e paradidáticos. A leitura e consequente absorção ou apreensão do saber que está nos livros pode ser facilitada ou dificultada pela forma como se apresentam os textos, ou seja, pela diagramação, pelo projeto gráfico, arranjo ou programação visual.

Quando se pensa em usar a leitura para promover o saber é necessário estreitar os laços entre o design de informação e o design instrucional ou educativo. Há de se usar este novo elemento transformador como aliado na educação 


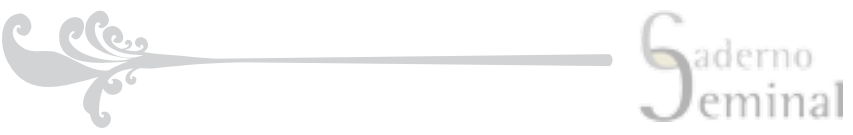

de cidadãos que, através do conhecimento e da consciência de seus direitos, compactuem para construir uma igualdade. Como sabiamente pontua De Masi (2010, p. 119-120), "não vale invocar o retorno ao 'direito natural'. É preciso um 'direito racional' e uma nova pedagogia que eduque os jovens para se transformarem em cidadãos, não em súditos."

Há, todavia, educação sem haver escola, conforme ensina Carlos Brandão (1983, p. 28). O educador defende o não abandono da educação na sua forma livre por ser a rede de trocas de saberes mais universal e mais persistente na sociedade humana. Ele afirma que o aprendizado é adquirido em espaços diversos, onde pessoas se reúnem e interagem em variadas atividades, ocorrendo assim a relação entre teoria e prática.

Um canal possível para essa educação livre é a leitura. Pensar em formas de facilitá-la é garantir a emancipação intelectual das pessoas para levá-las a uma autonomia prática. Numa visão macro, ainda segundo Brandão (1983, p. 28), a desigualdade da educação aparece quando surgem e se caracterizam os diversos tipos e graus de saber - já que com o capitalismo surge a possibilidade de mobilidade social por meio da educação de massa - isto é, uma situação provocada pela necessidade e interesse político de controle da sociedade, a partir do qual verifica-se a dicotomia entre o saber e poder.

Pensar a visão micro da educação que antes produzia a igualdade, e que hoje promove a desigualdade social como consequência da utilização da escola e dos sistemas pedagógicos para servir ao poder, é pensar num recomeço com a criação de novos padrões de organização. "Incorporar as visões e as razões da sociedade nos assuntos antes reservados aos governos, significa aumentar a possibilidade e a capacidade de as populações influírem nas decisões públicas - em poderar as comunidades, distribuir e democratizar o poder". (SILVEIRA, ano, p. 46)

É possível sugerir que pessoas se organizem para exigir que lhes chegue às mãos e aos olhos a informação, inclusive de forma organizada e adequada às suas realidades? Pode-se caracterizar esta prática como exemplo de uma nova dinâmica democrática? A perspectiva de ativar as consciências através de ações como o design de informação é como refutar a importância do desenvolvimento local, no momento presente. 


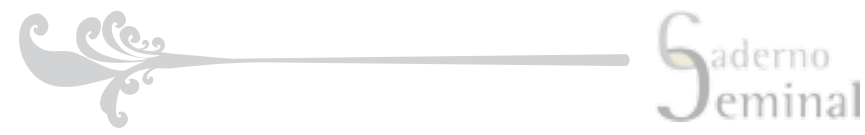

\section{REFERÊNCIAS}

ABAD, BRAIDA \& PONTES. Os sistemas híbridos do Design: despertando os sentidos. Anais do $5^{\circ}$ Congresso Internacional em Pesquisas em Design. Bauru, 2009. Disponivel em < http://www.raquelponte.com/publicacoes/sistemas_ hibridos_design.pdf>, acesso em 05 de setembro de 2011.

BOCCHINI, Maria Otília. Legibilidade Visual e Projeto Gráfico na Avaliação de Livros Didáticos pelo PNLD. Disponível em <http://www.abrale.com.br/wp-content/ uploads/legibilidade-visual-grafico-pnld.pdf>, acesso em 9 de outubro de 2011 .

BRANDÃO, Carlos Rodrigues. O que é Educação. São Paulo: Brasiliense, 1981.

DE MASI, Domenico. O Futuro Do Trabalho. Rio de Janeiro: José Olímpio, 2010.

MCLEAN, Ruari. The Thames and Hudson Manual of Typography. Londres: Thames and Hudson, 1997

MCLUHAN, Marshall. Os meios de comunicação como extensões do homem. Traduzido por Décio Pignatari. São Paulo: Cultrix, 1969.

PEIRCE, C S. Semiótica. São Paulo: Perspectiva, 1977.

PERELMAN \& OLBRECHTS-TYTECA. Tratado da argumentação: A nova retórica. Rio de Janeiro: Martins Fontes, 2005.

SILVEIRA Caio. "Desenvolvimento local e novos arranjos socioinstitucionais: Algumas referências para a questão da governança." In DOWBOR \& POCHMANN (orgs). Políticas para o Desenvolvimento Local. São Paulo: Perseu Abramo, 2010.

TSCHICHOLD, Jan. A forma do livro, ensaios sobre tipografia e estética do livro, Ateliê Editorial, 2007.

WALTHER-BENSE, E. A teoria geral dos signos: introdução aos fundamentos da semiótica. São Paulo: Perspectiva, 2000.

\section{Reconhecimentos:}

Trabalho desenvolvido no Programa de Pós- Graduação em Desenvolvimento Local do Centro Universitário Augusto Motta UNISUAM, Rio de Janeiro, Brasil 